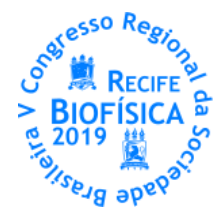

\title{
ENSINO DE BIOFÍSICA E COMPLEXIDADE: DIÁLOGOS NECESSÁRIOS
}

\author{
Mayara Gomes da Silva ${ }^{1 *}$, Márcia Adelino da Silva Dias², Karla Patrícia de Oliveira Luna ${ }^{3}$ \\ 1,2,3Grupo de Estudos da Complexidade e da Vida, UEPB; \\ *mayaragomesec@gmail.com
}

\begin{abstract}
INTRODUÇÃO
Há várias discussões na área da educação e do ensino de ciências, que criticam o modelo positivista, cartesiano, reducionista, enfatizando uma necessária superação desse paradigma, visto as mudanças decorrentes do desenvolvimento do pensamento científico e educacional. De fato, é preciso deslocar-se dessa visão mecanicista e compreender os processos educativos como sistêmicos, dialógicos e mutáveis. Por outro lado, de acordo com Moraes (2008), é preciso reconhecer que não se muda um paradigma educacional da noite para o dia, apenas colocando uma nova roupagem ou camuflando velhas teorias. Daí suscitam as seguintes indagações: o que fazer? Por onde começar?

Ajustando o foco para o ensino superior, especificamente para o ensino de Biofísica, várias lacunas apresentam-se como desafios para a compreensão dos temas e/ou conceitos científicos que permeiam essa área. Dentre estas, Cauduro e Luke (2016), destacam: as restrições dos conceitos da biologia ou da física, sem a devida relação entre eles; falta de professores específicos da área e de alternativas didáticas nesse campo; bem como, a escassez de pesquisadores e referenciais teóricos na área de ensino de Biofísica.
\end{abstract}

A Biofísica é um componente que integra o currículo de diversos cursos da área das Ciências Biológicas e da Saúde. É uma ciência interdisciplinar, complexa, uma vez que os temas estudados nessa área são frequentemente incluídos em outras, como a fisiologia, a bioquímica, além de ter desenvolvido áreas especificas de estudos, tais como, a biomecânica, bioeletricidade, radiobiologia, dentre outras (FRUMENTO, 1972; GARCIA, 2002). É um componente que contribui para que estudantes compreendam e posicionem-se criticamente frente a sociedade em que vivem e no mundo, sendo fundamental em temas que referem-se à qualidade de vida, contaminação ambiental, cuidado da saúde, benefícios e riscos do desenvolvimento científico e tecnológico, assim como sua relação com a política (MUÑOZ et al, 2013).

No intuito de refletir sobre alternativas que possibilitem as conexões dos conteúdos da Biofísica, no âmbito da complexidade, enfocamos aqui dois eixos que consideramos fundamentais: discutir a importância da Biofísica no processo formativo de estudantes das Ciências Biológicas; e tecer diálogos sobre a necessidade da religação dos conhecimentos da Biofísica com as outras áreas do conhecimento.

\section{MATERIAIS E MÉTODOS}

Este estudo foi desenvolvido em uma perspectiva qualitativodescritiva, tendo como aporte a pesquisa bibliográfica (GIL, 2008). Os resultados apresentados são parte de uma dissertação de mestrado em andamento, do Programa de Pós-Graduação em Ensino de Ciências e Educação Matemática, da Universidade Estadual da Paraíba.
Para atingir os objetivos da discussão proposta neste texto, buscamos dialogar com autores como Almeida (2008), Capra (2009), Muñoz et al (2013), Rocha (2017) e Moreira et al (2018), que discutem sobre a finalidade, desafios, relevância e conexões do ensino de Biofísica nas diversas esferas da vida humana.

\section{RESULTADOS E DISCUSSÃO}

A importância da Biofísica no processo formativo de estudantes das Ciências Biológicas

A Biofísica é essencial para compreender como são compostas as moléculas da vida, como partes diferentes de uma célula se movem e funcionam, e como sistemas complexos como, cérebro, circulação, sistema imunológico, funcionam. É um campo onde cientistas de várias áreas, incluindo matemática, química, física, engenharia, farmacologia e ciências dos materiais, usam suas habilidades para desenvolver alternativas que possibilitem a compreensão dos sistemas biológicos em sua dimensão complexa (BIOPHYSICAL SOCIETY, 2019).

Para exemplificar a relevância do ensino de biofísica no processo formativo de estudantes das Ciências Biológicas, destacamos a seguir algumas aplicações da biofísica no campo da biologia.

A começar pela Biofísica Molecular que abarca os níveis atômico e molecular, onde os principais processos estudados na área das Ciências Biológicas são as ligações do tipo: ponte de hidrogênio (DNA e RNA); ligações hidrofóbicas (que mantém estruturas proteicas e lipoprotéicas); ligação de Vander Waals (ligação entre antígeno-anticorpo, enzima-substrato); dipolo (característica da molécula de água); e ressonância (oscilação de elétrons entre duas partes de uma molécula - grupo carboxila dos aminoácidos) (HENEINE, 1991).

Além disso, de acordo com Rocha (2017), é necessário destacar a importância da molécula de água nos sistemas biológicos, uma vez que esta é um solvente universal com capacidade de reação com diferentes substancias, tais como, iônicas, covalentes e anfipáticas, o que torna possível a ocorrência de fenômenos elétricos, por exemplo, a propagação do impulso nervoso.

Essa constatação nos conduz aos estudos da Biofísica Celular, em que a célula é considerada um sistema autorreprodutivo de moléculas situadas nos limites de uma membrana, cujo modelo que melhor corresponde, é o do mosaico fluido (proteínas inseridas na bicamada lipídica), proposto por Jonathan Singer e Garth Nicolson (JUNQUEIRA, CARNEIRO, 2012; ROCHA, 2017).

Através de estudos sobre Bioeletricidade é possível compreender como se dá o potencial de repouso e ação de uma célula, o que viabiliza a permeabilidade da membrana celular a vários íons. Como exemplo, amplamente visto tanto na educação básica como no ensino superior, temos a bomba de sódio $\left(\mathrm{Na}^{+}\right)$e potássio $\left(\mathrm{K}^{+}\right)$, indispensável no processo de condução nervosa e comunicação 
celular. Também relaciona-se com a bioeletricidade, células capazes de se autoexcitar, produzindo de modo rítmico o potencial de ação. Tais células são responsáveis por iniciar movimentos biológicos repetitivos, como batimentos cardíacos e frequência respiratória (HENEINE, 1991; ROCHA, 2017).

É fundamental destacar as radiações como fatores que influenciam o desenvolvimento dos seres vivos. As radiações são emissões de energia, seja por meio de onda ou partículas, e podem ser classificadas como: ionizantes, capazes de gerar ionização da matéria, podendo ser do tipo alfa, beta, gama, ou raio-X; ou nãoionizantes, não causam ionização nos tecidos, apenas excitam os materiais biológicos acelerando as reações químicas, por exemplo a radiação ultravioleta, infravermelho e luz visível (MOURÃO, ABRAMOV, 2012; ROCHA, 2017).

De acordo com Mourão e Abramov (2012), as radiações não são boas nem ruins, vivemos expostos a estas $24 \mathrm{~h}$ por dia, 365 dias por ano. Podem ser naturais (sol, por exemplo) ou produzidas artificialmente para diversos fins, como para o tratamento do câncer, cozimento de alimentos no micro-ondas, exames de imagem de raio- $X$, dentre outros.

A Biofísica também contribui com o desenvolvimento de estudos que superem doenças, erradiquem a fome global, produzam fontes de energias renováveis, projetem tecnologias de ponta e apresentem resolução de problemas científicos, e da humanidade, tanto do presente, como do passado e do futuro (BIOPHYSICAL SOCIETY, 2019).

Por outro lado, as investigações e avanços no campo da Biofísica parecem estar na contramão das pesquisas em ensino e da prática docente. Para Moreira et al (2018), um dos maiores desafios da pesquisa em ensino de biofísica está ligado a ausência de materiais bibliográficos e produções acadêmicas a respeito dessa temática. Dentre as dificuldades de ensino deste componente observadas por docentes de Biofísica e apresentadas pelo autor supracitado, ressaltamos:

- Pouco conhecimento prévio do graduando, isto é, deficiências em Física e Matemática oriundas da educação básica, para lidar e identificar fenômenos biofísicos e os seus fundamentos físicos;

- Abordagem focalizada em memorização de fórmulas, conceitos, definições;

- Ausência de uma proposta pedagógica que seja significante e suficientemente justificável para a formação em Ciências Biológicas (MOREIRA et al, 2018).

Tecendo diálogos sobre a religação dos conhecimentos da Biofísica com as outras áreas do conhecimento

Antes de tudo é pertinente indagar: A Biofísica é a biologia da física ou a física da biologia?

Em 1996, Marco Bischof, levantou essa discussão e supôs que, talvez o fracasso da biofísica em desenvolver uma teoria da vida, estivesse relacionada à abordagem reducionista que postula que os processos da vida devem ser explicados por leis físico-químicas da natureza não-viva. Aproximadamente cinquenta anos antes, J. R. Loofbowrow (1940), escreveu que "não há um acordo explícito, mesmo entre os biofísicos, sobre o que o termo biofísica representa".

As investigações científicas no campo da Biofísica, por meio de instrumentos físicos, e a explicação de seus resultados utilizando conceitos físicos e matemáticos, têm sido realizadas desde 1840, e como disciplina separada, ela se estabeleceu apenas a partir da década de 1920, se não na década de 1940 (BISCHOF, 1996). No Brasil, tem-se como marco, a fundação do Instituto de Biofísica, no Rio de Janeiro, em 1945 (ALMEIDA, 2012).

Ainda nas primeiras décadas do século $X X$, houve um intenso debate entre os mecanicistas e vitalistas acerca dos fenômenos biológicos. Por um lado, os mecanicistas afirmavam que todos os fenômenos biológicos poderiam ser explicados pelas leis da física e da química. Por outro, os vitalistas defendiam a inserção de uma "força vital" a essas leis, constituindo um elemento extrafísico dos fenômenos biológicos (CAPRA, 2009).

Décadas depois, a ideia resultante desse debate, é que, para uma compreensão plena dos fenômenos biológicos, é preciso abordá-los em três níveis descritivos: a biologia dos fenômenos observados, as leis da física e da bioquímica e a dinâmica não- linear dos sistemas complexos (CAPRA, 2009). Tal abordagem conduz ao paradigma da teoria da complexidade.

Pensar no âmbito da complexidade é entender que nada está predeterminado, todo conhecimento é uma construção, podendo mudar a qualquer momento em função de emergências. 0 processo educativo é, portanto, o lugar onde se encontram estranhezas e familiaridades, saberes desconhecidos e já conhecidos, tanto por parte do estudante, quanto do docente. Não se trata de improvisação, consiste em experiências de diálogos e intersubjetividades, reflexões de indivíduos abertos a aprender, reinventar, criar (FÁVERO, TAUCHEN, 2013; MORAES, 2008). De acordo com Almeida (2008), a proposta central de uma educação para a complexidade está na religação e compartilhamento da diversidade dos saberes.

De acordo com Muñoz et al (2013), a Biofísica não é a união, nem a intersecção, nem a diferença entre a Física e a Biologia, e há algumas razões pelas quais os autores consideram apropriada e necessária uma didática da Biofísica, no sentido da religação de saberes e áreas do conhecimento no processo de ensinoaprendizagem deste componente. Dentre as razões apresentadas, destacamos:

- É preciso reconhecer o lugar da Biofísica no design curricular, seus campos de aplicação, dentre outros;

- Para melhorar a qualidade do ensino e aprendizagem de Biofísica, é preciso saber quais os conhecimentos prévios dos estudantes, seus erros mais comuns, seus preconceitos, seus interesses e atitudes com relação a este componente;

- A Biofísica não se reduz à memorização e aplicação de fórmulas e conceitos, é necessário abrir espaço para a abordagens de situações reais, contextualizadas;

- A didática da biofísica pode colaborar no estabelecimento de relações com outros campos do conhecimento, como a História da Ciência, em particular da Biofísica, a didática geral, da física e da biologia, a epistemologia da Biofísica, dentre outros;

- Incentivar a pesquisa sobre o ensino e a aprendizagem da Biofísica, sua divulgação científica, a adequada formação de professores, a produção de textos e softwares apropriados, a abordagem desse componente na educação escolar, e para a sociedade em geral, são aspectos relevantes de uma didática da biofísica e pilares para o desenvolvimento tecnológico e científico de um país (MUÑOZ et al, 2013).

Para os autores, ser um especialista em Biofísica não implica apenas em saber como facilitar o aprendizado para os estudantes. É necessário reconhecer os problemas inerentes a esse campo, tais como, aqueles que dificultam o ensino-aprendizagem tanto de estudantes como de professores desta área (MUÑOZ et al, 2013).

Em seu livro "Para entender la complejidad", Almeida (2008), discute um conjunto de argumentos que ajudam a entender o que é a complexidade. Dentre os argumentos apresentados, convém salientar, a colocação de Hubert Reeves, apresentada pela autora, que diz respeito as novas propriedades emergentes nas combinações, que não existiam em absoluto nos elementos isolados, por exemplo, "a molécula de água é um excelente solvente, que não é de forma alguma o hidrogênio e o oxigênio que a compõem". De modo semelhante, a Biologia e a Física possuem aspectos particulares intrínsecos que as constituem como áreas do 
saber com os seus objetos de estudos e especificidades; a Biofísica, portanto, mesmo constituindo um elo, uma religação de saberes dessas áreas, não é de forma alguma estritamente física ou biológica, ou apenas, uma mera aplicação de conceitos e definições de uma área a outra. É um campo científico onde é necessário reconhecer e compreender a sua complexidade.

\section{CONCLUSÕES}

Nesse texto, discutimos sobre a relevância da biofísica no contexto das Ciências Biológicas, bem como os diálogos necessários com a complexidade. No campo da Biologia, a Biofísica é essencial para compreender a dinâmica da vida, abarcando áreas como a Biofísica Molecular, Celular, Bioeletricidade, Radiologia, dentre outras aplicações que contribuem para a sensibilização e formação profissional e humana.

Retornando a questão proposta no início deste trabalho, considerando que os modos fragmentados e unilaterais de pensar e conceber os processos de ensino-aprendizagem já não dão conta de explanar o ensino de Biofísica, foi proposto ao longo das discussões, um repensar sobre esse assunto no âmbito da complexidade.

Pensar a dimensão complexa da Biofísica é, portanto, dialogar com diversas áreas do conhecimento, reconhecendo que nada está isolado, nenhum conhecimento é fixo e imutável, e que existem múltiplas dimensões do saber, do fazer e do saber fazer ciência, educação e ensino de ciências, particularmente, ensino da biofísica.

É importante salientar que uma didática da Biofísica não implica o isolamento de conteúdos e especificidades desta área, ou limitar a abordagem desse componente a fórmulas, memorizações, repetições de definições, conceitos, dados. Pelo contrário, é reconhecer a dimensão complexa que esse componente assume na formação de profissionais, que antes de tudo, são seres humanos.

Essa necessária conversa sobre o ensino de biofísica deve perpassar o entendimento das instituições de ensino superior acerca da sua importância como ciência-base, deve, ainda, conter introdução direcionada dos conceitos de Física nos primeiros períodos do ensino da graduação, e, não menos importante, deve ser impulsionada pelos docentes através de pesquisa bibliográfica e de bancada.

\section{REFERÊNCIAS}

ALMEIDA, D. F. A contribuição de Carlos Chagas Filho para a institucionalização da pesquisa científica na universidade brasileira. História, Ciências, Saúde - Manguinhos, Rio de Janeiro, v.19, n.2, abr.-jun. 2012.

ALMEIDA, M. C. Para comprender la complejidad. Multiversidad mundo real Edgar Morin. México, DFAC Hermosillo, 2008.

$\mathrm{BISCHOF}, \mathrm{M}$. Some remarks on the history of Biophysics (and its future). Current Development of Biophysics, v. 22, 1996.

BIOPHISICAL SOCIETY. What is Biophisics? Disponível em: <https://www. biophysics.org/what-is-biophysics> Acesso em: 14 fev. 2019.

CAPRA, F. As conexões ocultas: ciência para uma vida sustentável. $11^{\mathrm{a}}$ ed. São Paulo: Cultrix, 2009.

CAUDURO, P. J.; LUDKE, E. Revisão bibliográfica sobre o ensino de biofísica: uma análise de artigos de 2004 a 2016. Vivências. Vol. 13, N.24: p.418-424, Maio/2017.

FÁVERO, A. A.; TAUCHEN, G. Epistemologia da complexidade e didática complexa: princípios e desafios. Educação e Filosofia. Uberlândia, v. 27, n. 53, p. 175-192, jan. /jun. 2013.

FRUMENTO, A. S. Biofísica, Antonio S. Frumento. México: Editora Intermédica, 1972.

GARCIA, E. A. C. Biofísica. São Paulo: SARVIER, 2002.
GIL, A. C. Como elaborar projetos de pesquisa. 4. ed. São Paulo: Atlas, 2008.

HENEINE, I. F. Biofísica básica. 2. Reemp. Rio de Janeiro: Atheneu Editora, 1991.

JUNQUEIRA, L.; CARNEIRO, J. Biologia Celular e Molecular. 9.ed. Rio de Janeiro: Guanabara Koogan, 2012.

MORAES, M. C. O paradigma educacional emergente: implicações na formação do professor e nas práticas pedagógicas. Em aberto, v. 16, n. 70, 2008.

MOREIRA, C. H.; ROCHA, G. B.; TENÓRIO, A. C.; SILVA, R. M.; ROCHA, I. C. P. A Biofísica na formação do biólogo e a opinião dos docentes formadores da área. In: Anais do $16^{\circ}$ Congresso Internacional de Tecnologia na Educação Brasil. Recife - PE, Setembro de 2018.

MOURÃO, C. A.; ABRAMOV, D. M. Biofísica essencial. Rio de Janeiro: Guanabara Koogan, 2012.

MUÑOZ, J. C.; FLORES, M. V.; CASSIBBA, R. POR QUÉ ES NECESARIA UNA DIDÁCTICA DE LA BIOFÍSICA. ANALES AFA. Vol. 23. No. 1. 2013.

ROCHA, G. B. Perspectivas docentes e curriculares da Biofísica nos cursos de Bacharelado em Ciências Biológicas na contemporaneidade. Dissertação de Mestrado - Universidade Federal Rural de Pernambuco, Programa de Pós-Graduação em Ensino das Ciências, Recife - PE, 2017. 